\title{
The Winter Diurnal Circulation and Its Influence on Precipitation over the Coastal Area of Northern Taiwan
}

\author{
GeORGE TAI-JEN CHEN \\ Department of Atmospheric Sciences, National Taiwan University, Taipei, R.O.C. \\ SHI-YANG CHEN \\ Chinese Central Weather Bureau, Taipei, R.O.C. \\ MIIN-HUEY YAN ${ }^{1}$ \\ Department of Atmospheric Sciences, National Taiwan University, Taipei, R.O.C. \\ (Manuscript received 21 January 1983, in final form 21 July 1983)
}

\section{ABSTRACT}

\begin{abstract}
Wind and rainfall data for December, January and February, 1976-80, over the northern coastal area of Taiwan were analyzed to examine the diurnal patterns of these parameters. Results show that the diurnal variation of rainfall was strongly modulated by the diurnal cycle of local circulation. Local circulations exhibit maximum onshore flow and divergence at 1400 LST and maximum offshore flow and convergence in 02000500 LST. Convective heavy rainfall appears to be triggered by the diurnal divergence pattern. Finally, the diurnal rainfall was primarily controlled by the dynamical processes within the planetary boundary layer and the thermodynamic process only plays a minor role in modifying the temporal rainfall pattern.
\end{abstract}

\section{Introduction}

Chen et al. (1980) studied a case of mesoscale heavy rainfall, with a daily total of $\sim 100 \mathrm{~mm}$ over northern Taiwan, under a northeast monsoon regime during the period of 15-17 December 1979. Their analyses suggested that the local horizontal convergence in the boundary layer was an essential component for the rainfall and seemed to be mainly due to the differential friction between land and sea and to the interactions between diurnal local circulation and large-scale northeast monsoonal flow. Chen and Liu (1981) studied the climatology of the mesoscale heavy rainfall phenomenon under the winter northeast monsoonal flow regime over the same area during the period of October-March, 1969-80. They found that the frequency distribution of the starting time of abnormally heavy rainfall (AHR) for 34 cases exhibits a bimodal pattern with the first peak at 0600-0800 LST and the second one at 1800-2000 LST. The AHR was defined as the daily rainfall being two standard deviations greater than the monthly normal. They tentatively attributed the morning and the late afternoon maximum to the diurnal variation of local convergence and daytime boundary layer heating, respectively. Winter rainfall over northern Taiwan seems to possess distinct

\footnotetext{
${ }^{1}$ Present affiliation: Geophysics Institute, University of Alaska, Fairbank 99701.
}

diurnal variability and is, perhaps, related to the local circulation.

Diurnal variability of rainfall has been a well-known feature for years at different latitudes and in different months. A large number of articles have been published on these subjects in the past years. Wallace (1975) classified numerous mechanisms that have been proposed to explain these diurnal variations into two categories: 1) those based on thermodynamic processes that affect the static stability, and 2) those based on dynamical processes that influence the mass convergence within the planetary boundary layer. Regarding the dynamical processes, many studies in recent years have described the importance of local diurnal circulation in modulating the diurnal rainfall in various locations. For example, Kousky (1980) observed that the diurnal variation of rainfall in northeast Brazil is modulated by sea-land and mountain-valley wind circulations. Houze et al. (1981) found that the diurnal cycles of cloudiness and precipitation over land and sea near North Borneo in winter were modulated by a strong diurnal cycle of land-sea circulation which was superimposed on the northeasterly monsoon current at low levels. Schwartz and Bosart (1979) and Burpee (1979) examined the influence of sea breeze convergence on the diurnal variation of precipitation over the Florida Peninsula. Passarelli and Braham (1981) studied the role of the land breeze in the formation of Great Lake winter snow storms. Mass (1982) found that the diurnal variation of rainfall over western 
Washington State was controlled by the topographically forced diurnal circulations. The purpose of this paper is to study these problems further over northern Taiwan. The diurnal variations in wind and rainfall were analyzed over the coastal area of northern Taiwan for the winter season. The influence of the local circulation on the diurnal variation of rainfall was examined.

\section{Data and analyses}

The data for this investigation consisted of 3-hourly precipitation and wind measurements as recorded at Keelung (Fig. 1) for the period of December-February 1976-80. Keelung was chosen because it is the only station located on the windward side facing the northeast monsoonal flow in winter over the northern coast of Taiwan. The 3-h accumulated rainfall was reported at observation time. For example, 0500 LST refers to the period 0201-0500 LST. The diurnal rainfall variations were obtained at $3 \mathrm{~h}$ intervals for each month. Resultant (or vectorially averaged) surface winds were computed at each observation time, and then the daily mean resultant wind was removed to generate the deviation winds. These deviation winds represent the diurnal, predominantly locally driven component of the air flow. To show the mean regional-scale circulations, resultant winds at Pengchiayu (about $65 \mathrm{~km}$ to the northeast of Keelung) and six stations in northern Taiwan (Fig. 1) were also computed.

To examine the divergence resulting from the interactions between the local circulation and the largescale prevailing wind, the wind measurements at Pengchiayu are taken as representative values over the water. Thus, the divergence field computed from the resultant winds at Keelung and Pengchiayu as shown in Fig: 2 represents the mean local divergence $(\bar{D})$ over the coastal region due to land-sea differential friction. Since the diurnal amplitude of the resultant wind is only about $5 \%$ of the mean resultant wind speed at Pengchiayu as compared to $20 \%$ at Keelung, the diurnal cycle of the wind field at Pengchiayu was neglected

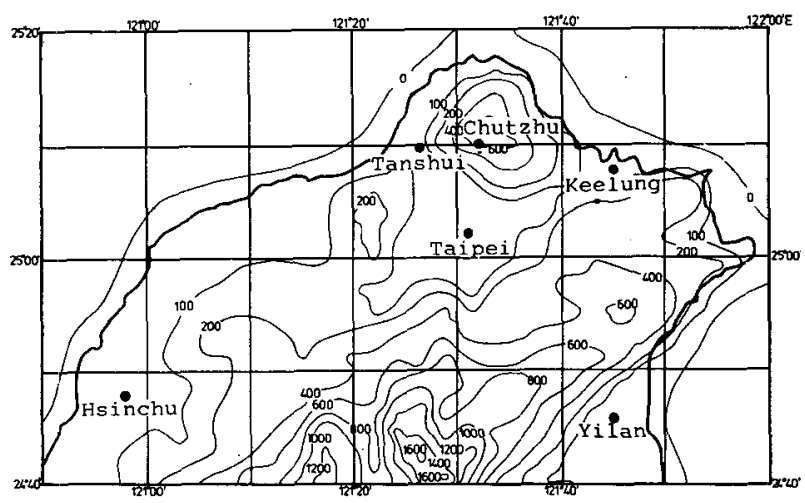

FIG. 1. Smoothed topography $(m)$ and location of surface stations over northern Taiwan. Pengchiayu is located at $25^{\circ} 38^{\prime} \mathrm{N}, 122^{\circ} 04^{\prime} \mathrm{E}$ (not shown).
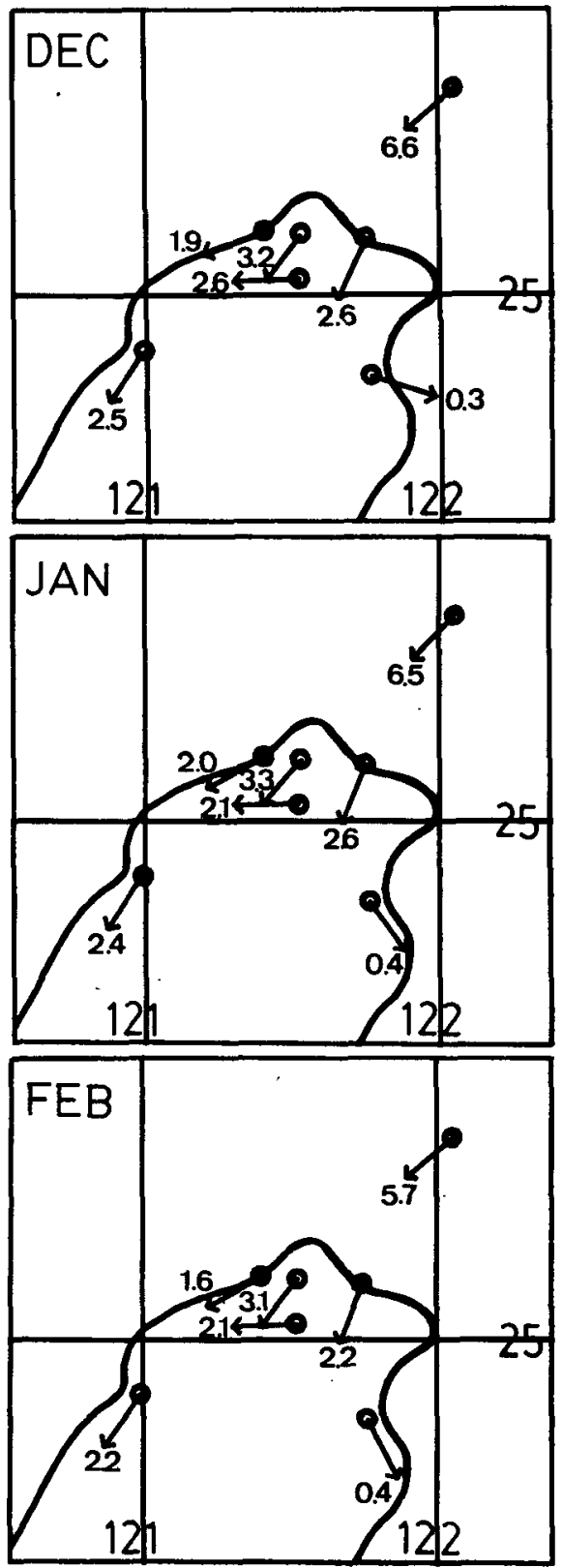

Fig. 2. Resultant surface winds in December, January and February, 1976-80. Speed in $\mathrm{m} \mathrm{s}^{-1}$.

in the divergence computation. The total divergence $(D)$ at each observation time was computed using the resultant wind at that time at Keelung and the mean resultant wind at Pengchiayu. The mean divergence $\bar{D}$ was then removed from the total divergence $D$ at each observation time to obtain the deviation divergence $\left(D^{\prime}\right)$ due to local wind circulation. Because the resultant winds at Keelung and Pengchiayu are approximately in the same direction (Fig. 2) and also the diurnal wind circulations are primarily in the same or opposite direction as resultant wind at Keelung (Fig. 3 ), therefore, the divergence was computed using the 

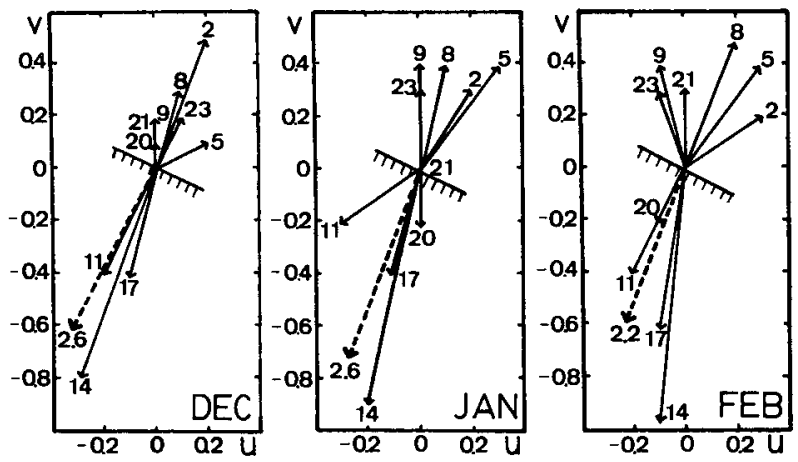

FIG. 3. Hodographs of surface winds at Keelung observed at 0200 , $0500,0800,0900,1100,1400,1700,2000,2100$, and 2300 LST averged over 1976-80 for December, January and February with the daily mean resultant wind removed. The daily mean resultant wind in each month is shown by dashed arrow in $\mathrm{m} \mathrm{s}^{-1}$. Coastal line oriented in a northwest-southeast direction is indicated with land hatched. Abscissa is east-west component of wind and ordinate the north-south component in $\mathrm{m} \mathrm{s}^{-1}$.

component along the resultant wind direction at Keelung.

\section{Climatology of the region}

Northern Taiwan is approximately centered at $25^{\circ} \mathrm{N}$ between 121 and $122^{\circ} \mathrm{E}$ as shown in Fig. 1. The Central Mountain Range runs approximately in a north-south direction across Taiwan Island with its ridge extending northeastward in northern Taiwan. Keelung is a surface station along the northern coast and is geographically connected to Taipei by the northeast-southwest oriented Keelung Valley. In the vicinity of Keelung, mountains with averaged height of $600 \mathrm{~m}$ are located $20 \mathrm{~km}$ to the west and south.

The climate of the northern coastal region of Taiwan can be reasonably well described by observations at Keelung, which is characterized by wet winter-dry summer. The winter months (December-February) have the highest mean daily rainfall and precipitation probability $70-80 \%$ and least sunshine duration (15\% of maximum possible) at Keelung (Chen, 1977). Fig. 2 shows the resultant winds in northern Taiwan for December-February. It is clear that the wind speed and direction at each station are rather persistent throughout the winter months. The northeast monsoonal flow prevails over the area except at Taipei and Yilan where easterly and northwesterly winds were observed, respectively. The easterlies at Taipei can be attributed to the deflecting effect of the northeasterlies by the Keelung Valley to the east-northeast of Taipei and the high terrain to the south (see Fig. 1). To the east of the Central Mountain Range, the northeasterlies tend to follow the contour and turn cyclonically in the vicinity of Yilan resulting in weak northwesterlies. Over the sea, as observed at a small island to the northeast (Pengchiayu), the northeasterlies are much stronger than those observed over the land, presumably owing to the land-sea differential friction. Convergence over the northern coastal area due to this differential friction is rather evident and persistent throughout the winter months.

Figure 4 shows the annual variation of monthly mean sea surface temperature (SST) in the vicinity of Keelung (Robinson, 1976) and the monthly mean of daily maximum, minimum, and mean temperatures at Keelung. The SSTs are much higher than the mean temperatures except in the months of July-September when the former are slightly lower than the latter. One notes that the differential between SST and daily minimum temperature is largest in December-February. During these months, the water temperature exceeds the minimum temperature over land by $\sim 7^{\circ} \mathrm{C}$, while the water temperature is very close to the maximum temperature.

\section{Diurnal variation of wind and divergence}

Deviation winds as shown in Fig. 3 represent the components of diurnal local circulation. One notes that onshore flow prevails during the daytime period, whereas offshore flow dominates at nighttime hours for each month. The onshore flow reaches a maximum at 1400 LST and the maximum offshore flow usually occurs in the early morning hours (0200-0800 LST). Since the prevailing wind (mean resultant wind) is onshore from the northeast (Fig. 2), the local circulation would be expected to enhance the local convergence at night and to suppress the convergence in the daytime hours.

The divergence due to local circulation at $3 \mathrm{~h}$ intervals and mean divergence due to differential friction for each month are shown in Table 1. Divergence (positive $D^{\prime}$ ) occurs during the daytime hours and reaches a maximum value at 1400 LST for each month. The maximum divergence counteracts the mean convergence $(\bar{D})$ by about $30 \%$. Convergence (negative $D^{\prime}$ ) occurs at night and in the early morning and reaches

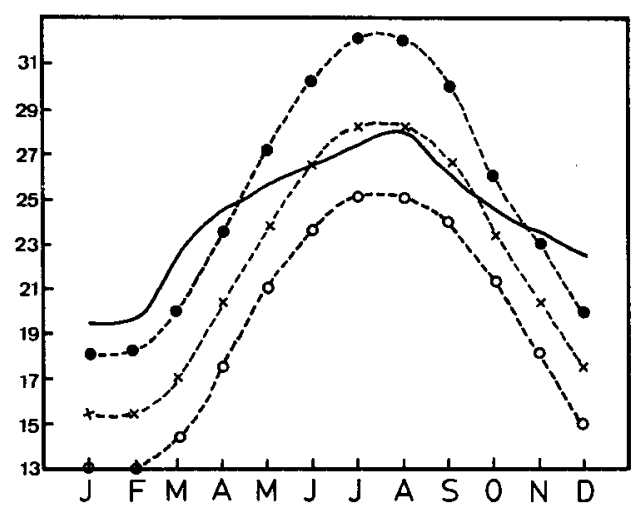

FIG. 4. Annual variation of monthly mean sea surface temperature in the vicinity of Keelung (solid, Robinson, 1976) and the monthly mean of daily maximum (solid circle), minimum (open circle), and mean (crossed) temperatures (dashed) at Keelung. Ordinate is temperature in ${ }^{\circ} \mathrm{C}$. 
TABLE 1. Diurnal variation of horizontal divergence due to local circulation $\left(D^{\prime}\right)$ and mean divergence $(\bar{D})$ due to land-sea differential friction along the northern coast of Taiwan for December, January and February 1976-80. Unit in $10^{-5} \mathrm{~s}^{-1}$.

\begin{tabular}{lccccccccc}
\hline & \multicolumn{8}{c}{ Local standard time } \\
\cline { 2 - 10 } Month & 0200 & 0500 & 0800 & 1100 & 1400 & 1700 & 2000 & 2300 \\
\hline Dec & -1.2 & -0.4 & -0.5 & 0.8 & 1.5 & 0.6 & -0.2 & -0.4 & -5.8 \\
Jan & -0.7 & -0.8 & -0.7 & 0.5 & 1.5 & 0.7 & 0.3 & -0.5 & -5.5 \\
Feb & -0.5 & -0.9 & -0.9 & 0.6 & 1.6 & 1.0 & 0.3 & -0.4 & -4.8 \\
Mean & -0.8 & -0.7 & -0.7 & 0.6 & 1.5 & 0.8 & 0.1 & -0.4 & -5.4 \\
\hline
\end{tabular}

a maximum at 0200 LST in December and 0500 LST in January and February. The maximum convergence adds to the mean convergence by $15-20 \%$. The diurnal variation of divergence due to local circulation averaged over December-February is shown in Fig. 5. The amplitude of this divergence field is about $0.8-1.5\left(\times 10^{-5}\right)$ $\mathrm{s}^{-1}$ which represents $15-30 \%$ of the mean divergence in winter.

As shown in Fig. 4, the SST is higher than the daily maximum temperature in winter. Thus, no sea breeze can develop in the daytime. The onshore flow that develops in the daytime, therefore, must be induced by the upslope wind which was generated in the Keelung Valley due to uneven solar heating between the mountain slope and the free atmosphere at the same level. At night, on the other hand, downslope wind develops due to the uneven radiational cooling. Although downslope winds are usually rather weak, they are presumably enhanced by the land breeze which can theoretically form in this case as the SST is much higher than the temperature over land. As a result, the offshore flow reaches a maximum intensity comparable to the onshore flow. Topographically forced slope winds would produce clockwise turning for isolated slopes

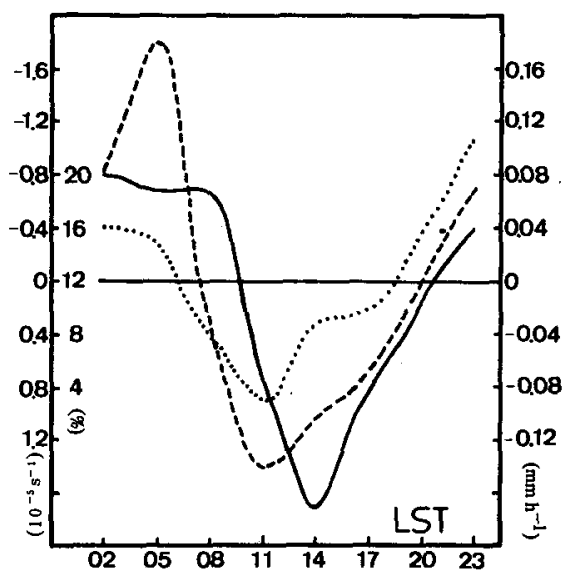

FIG. 5. Diurnal variation of horizontal divergence $\left(10^{-5} \mathrm{~s}^{-1}\right)$ due to local circulation (solid), mean hourly rainfall $\left(\mathrm{mm} \mathrm{h}^{-1}\right)$ with daily mean removed (dashed), and the percentage frequency distribution (\%) of the beginning time for rainfall rate $\geqslant 3.0 \mathrm{~mm} \mathrm{~h}^{-1}$ (dotted) averaged over December-February, 1976-80 at Keelung. (not in a valley) as shown by theoretical (Holton, 1967) and observational (Buajitti and Blackadar, 1957) studies. No systematic turning of the wind can be detected in this case (Fig. 3), however, possibly due to the complex interactions of the slope winds developed to the west and south of Keelung.

\section{Diurnal variation of precipitation}

Diurnal variations of rainfall and the deviations of hourly rainfall from the daily mean in winter months are shown in Table 2 . The daily mean of the hourly rainfall is very persistent for each month with a mean of $0.41 \mathrm{~mm} \mathrm{~h}^{-1}$ averaged over December-February. The rainfall reaches a maximum in the early morning hours between 0200 and 0500 LST and then decreases to a minimum at the middle of the day between 1100 to 1400 LST in each month. As can be easily seen from the deviations that the rainfall is suppressed during the daytime hours and enhanced from midnight to the early morning. There is $40 \%$ of rainfall occurring in $0800-1700$ LST and $60 \%$ in $2000-0500$ LST averaged over three months. Diurnal variations of the deviation rainfall averaged over three months are also shown in Fig. 5 for comparison. It is clear that the maximum occurs at 0500 LST and minimum at 1100 LST.

To examine the possible role of the diurnal cycle in triggering rainfall events, the number of rainfall events beginning in each $3 \mathrm{~h}$ interval was calculated at the thresholds of $\geqslant 0.1, \geqslant 1.0, \geqslant 3.0$, and $\geqslant 5.0 \mathrm{~mm}$ $\mathrm{h}^{-1}$. These thresholds will be referred to as category I, II, III, and IV, respectively. Diurnal variations of the percentage frequency of the rainfall beginning time for different categories of rainfall rate are shown in Table 3. Category I has a rather uniform frequency distribution although it exhibits a detectable double peak at 0500 and 1700 LST. Half of the "all rainfall" events begin in the daytime and another $50 \%$ at night for category $\mathbf{I}$. The diurnal variation becomes more evident for greater rainfall intensity. As the rainfall rate increases, the rainfall beginning time tends to be more favorable at night (2000-0500 LST) than in the daytime (0800-1700 LST). It can be observed that the frequency at night increases from $50 \%$ for category I to $60 \%$ for category II, $70 \%$ for category III and $72 \%$ 
TABLE 2. Diurnal variation of the rainfall $\left(\mathrm{mm} \mathrm{h}^{-1}\right)$ for December, January and February 1976-80. Parentheses are deviation from the daily mean in each month.

\begin{tabular}{lccccccccc}
\hline \hline & \multicolumn{10}{c}{ Local standard time } \\
\cline { 2 - 11 } Month & 0200 & 0500 & 0800 & 1100 & 1400 & 1700 & 2000 & 2300 & Mean \\
\hline Dec & 0.42 & 0.54 & 0.27 & 0.25 & 0.24 & 0.35 & 0.41 & 0.38 & 0.36 \\
& $(0.06)$ & $(0.18)$ & $(-0.09)$ & $(-0.11)$ & $(-0.12)$ & $(-0.01)$ & $(0.05)$ & $(0.02)$ & \\
Jan & 0.58 & 0.54 & 0.44 & 0.29 & 0.33 & 0.31 & 0.37 & 0.54 & 0.43 \\
& $(0.15)$ & $(0.11)$ & $(0.01)$ & $(-0.14)$ & $(-0.10)$ & $(-0.12)$ & $(-0.06)$ & $(0.11)$ & \\
Feb & 0.47 & 0.68 & 0.44 & 0.28 & 0.37 & 0.35 & 0.45 & 0.53 & 0.45 \\
& $(0.02)$ & $(0.23)$ & $(-0.01)$ & $(-0.17)$ & $(-0.08)$ & $(-0.10)$ & $(0)$ & $(0.08)$ & \\
\multirow{2}{*}{ Mean } & 0.49 & 0.59 & 0.39 & 0.27 & 0.31 & 0.34 & 0.41 & 0.48 & 0.41 \\
& $(0.08)$ & $(0.18)$ & $(-0.02)$ & $(-0.14)$ & $(-0.10)$ & $(-0.07)$ & $(0)$ & $(0.07)$ & \\
\hline
\end{tabular}

for category IV. For categories III and IV, presumably of a convective nature, the frequency peak at midnight and early morning is more remarkable. Thus, the more intense rainfall events tend to be more strongly modulated by the diurnal cycle. Since the number of occurrences for category IV is much less than that for category III for the analyzed 5-year data and thus, perhaps, less representative, only percentage frequency for category III is shown in Fig. 5 for discussion. The diurnal variation in this frequency is very evident with a minimum at 1100 LST and a maximum at 2300 LST.

\section{Concluding remarks}

Northern coastal area of Taiwan faces the East Asian northeast monsoonal flow in winter. The northeasterlies prevail over northern Taiwan and the adjacent ocean as shown in the resultant wind field (Fig. 2). Boundary layer convergence due to the land-sea differential friction causes a wet winter over this area. At the same time, the local diurnal wind circulation is very evident over northern coastal area (Fig. 3). In this study, wind and rainfall in winter months of December-February 1976-80 were analyzed to reveal the diurnal variabilities and their interrelations. Onshore flow develops during the daytime hours and reaches a maximum at $1400 \mathrm{LST}$. Offshore flow, on the other

TABLE 3. Diurnal variations of the percentage frequency (\%) of the rainfall beginning time for different categories of rainfall rate $\left(\mathrm{mm} \mathrm{h}^{-1}\right)$ during the period of December-February 1976-80. Day represents 0800-1700 LST and night 2000-0500 LST.

\begin{tabular}{rrrrrrrrrr}
\hline & \multicolumn{8}{c}{ Local standard time } \\
\cline { 2 - 10 } Category & 02 & 05 & 08 & 11 & 14 & 17 & 20 & 23 & Day/night \\
\hline I $\geqslant 0.1$ & 12 & 14 & 10 & 12 & 12 & 16 & 14 & 10 & $50 / 50$ \\
II $\geqslant 1.0$ & 10 & 15 & 12 & 7 & 12 & 9 & 16 & 19 & $40 / 60$ \\
III $\geqslant 3.0$ & 16 & 15 & 8 & 3 & 9 & 10 & 16 & 23 & $30 / 70$ \\
IV $\geqslant 5.0$ & 13 & 31 & 4 & 4 & 7 & 13 & 7 & 21 & $28 / 72$ \\
\hline
\end{tabular}

hand, develops at night and reaches a maximum with comparable magnitude in the early morning hours of 0200-0800 LST. The interactions between the local circulation and the prevailing large-scale northeast monsoonal flow generate a diurnal divergence pattern with convergence at night and divergence in the daytime having an amplitude of $0.8-1.5\left(\times 10^{-5}\right) \mathrm{s}^{-1}$. This diurnal divergence field counteracts or adds to the mean divergence field due to the land-sea differential friction by $15-30 \%$. As a result, local convergence reaches a maximum in the early morning (0200-0500 LST) and a minimum in the afternoon (1400 LST) over northern coastal area. Dynamically, this diurnal variation of the mass convergence within the planetary boundary layer ought to influence the rainfall variation. In fact, this is observed in this study. Rainfall is suppressed in the daytime when local convergence is weak and is enhanced at night when local convergence is strong. The rainfall in the daytime is much less than that at night, being $40 \%$ versus $60 \%$. The diurnal rainfall pattern is positively correlated with the convergence pattern. It reaches a maximum at 0500 LST and a minimum at $1100 \mathrm{LST}$. Thus, the diurnal variation of rainfall is strongly modulated by the local convergence, which in turn is controlled by the diurnal local circulation. The local circulations are primarily due to the topographically forced slope winds and perhaps enhanced by land breeze at night.

Rainfall beginning time favors at night especially for greater rainfall intensity. Percentage frequency of the rainfall beginning time during the daytime period is $50 \%$ for category $I\left(\geqslant 0.1 \mathrm{~mm} \mathrm{~h}^{-1}\right)$ and increases to $60 \%$ for category II $\left(\geqslant 1.0 \mathrm{~mm} \mathrm{~h}^{-1}\right)$, to $70 \%$ for category III $\left(\geqslant 3.0 \mathrm{~mm} \mathrm{~h}^{-1}\right)$ and to $72 \%$ for category IV $(\geqslant 5.0$ $\mathrm{mm} \mathrm{h}^{-1}$ ). The frequency of rainfall beginning time for category III of a convective nature is highly correlated with the local convergence (Fig. 5). This indicates that the local convergence is primarily responsible for triggering heavy rainfall in winter under the prevailing northeast monsoonal flow. Thus, the mechanism proposed by Chen and Liu (1981) to explain the peak 
frequency of the starting time for the abnormally heavy rainfall observed in the early morning (0600-0800 LST) is further substantiated.

As shown in Fig. 5, both diurnal variations of rainfall and frequency of rainfall starting time are highly correlated with variation of the divergence field due to the local circulation. However, they are not quite in phase. While the deviation divergence reaches a maximum at 1400 LST, the rainfall is a minimum at 1100 LST. This is possibly due to the daytime solar heating which reaches a maximum at 1400 LST and causes a minimum static stability. This will, in turn, cause the rainfall to increase in the afternoon despite the decrease in local convergence. The maximum rainfall occurring at $0500 \mathrm{LST}$ is perhaps due to the decrease of static stability caused by the nighttime infrared radiational cooling effect at the cloud top in addition to the local convergence. Therefore, the diurnal rainfall variability over northern coastal area of Taiwan is primarily modulated by the dynamical processes. Thermodynamic process seems to play a minor role in modifying the temporal rainfall distribution.

In view of these observations, it would be expected that organized regional studies might produce useful information relevant to local weather forecasting. Results of this study suggest that thermally forced diurnal local circulations and their interactions with the larger scale flow over northern Taiwan should be considered in future studies of regional mesoscale models.

Acknowledgments. We would like to thank the official reviewers for useful suggestions. The work was supported by the National Science Council of R.O.C. under Grant NSC72-0202-M002-11.

\section{REFERENCES}

Buajitti, K., and A. K. Blackadar, 1957: Theoretical studies of diurnal wind structure variations in the planetary boundary layer. Quart. J. Roy. Meteor. Soc., 83, 486-500.

Burpee, R. W., 1979: Peninsula scale convergence in the south Florida sea breeze. Mon. Wea. Rev., 107, 852-860.

Chen, G. T. J., 1977: An analysis of climatological references for subjective probability weather forecasting in Taiwan. Tech. Rep. No. Prob-Fore-001, Dept. Atmos. Sci., National Taiwan University, Taipei, R.O.C. 107, 85 pp. (in Chinese with English abstract).

—, C. W. Lee and K. Y. Liu, 1980: A preliminary study of abnormal rainfall over northern Taiwan under the northeast monsoon influence in winter season. Atmos. Sci., Meteor. Soc. R.O.C., 7, 73-84 (in Chinese with English abstract).

- - and K. Y. Liu, 1981: On the winter abnormal heavy rainfall (AHR) over northern Taiwan. Pap. Meteor. Res., 4, 1-12.

Holton, J. R., 1967: The diurnal boundary layer wind oscillation above sloping terrain. Tellus, 19, 199-205.

Houze, R. A., Jr., S. G. Geotis, F. D. Marks, Jr. and A. K. West, 1981: Winter monsoon convection in the vicinity of North Borneo. Part I: Structure and time variation of the clouds and precipitation. Mon. Wea. Rev., 109, 1595-1614.

Kousky, V. E., 1980: Diurnal rainfall variation in northeast Brazil. Mon. Wea. Rev., 108, 488-498.

Mass, C., 1982: The topographically forced diurnal circulations of western Washington State and their influence on precipitation. Mon. Wea. Rev., 110, 170-183.

Passarelli, R. E., and R. R. Braham, 1981: The role of the winter land breeze in the formation of Great Lake snow storms. Bull. Amer. Meteor. Soc., 62, 482-491.

Robinson, M. K., 1976: Atlas of North Pacific Ocean Monthly Mean Temperatures and Mean Salinities of the Surface Layer. NOORP-2, Naval Oceanographic Office, Washington, DC 20373.

Schwartz, B. E., and L. F. Bosart, 1979: The diurnal variability of Florida rainfall. Mon. Wea. Rev., 107, 1535-1545.

Wallace, J. M., 1975: Diurnal variations in precipitation and thunderstorm frequency over the conterminous United States. Mon. Wea. Rev., 103, 406-419. 